\title{
PHARMACOLOGY OF TRANQUILLIZING DRUGS
}

\author{
BY
}

\author{
MARTHE VOGT, M.D., Ph.D., F.R.S. \\ Department of Pharmacology, Edinburgh University
}

By definition "tranquillizers" cause sedation without, as a rule, clouding consciousness. Because these substances change the responsiveness to external stimuli and influence processes of emotion and thought, specialized neurological and psychological methods are required to assess their efficacy. In order to use the drugs judiciously, it is desirable to know as much as possible about the nature of their action.

The tranquillizers can be classified into two main groups. The first comprises the drugs used mainly in psychoses (reserpine, chlorpromazine, and their congeners), while the second group consists of substances predominantly administered to patients suffering from neuroses or to normal people undergoing a severe emotional or physical ordeal.

\section{DRUGS USED MAINLY IN PSYCHOSES}

The members of the first group have in common the production of profound alterations in brain metabolism, but. in spite of great similarity in the indication for their use, in the therapeutic effects obtained, and in some of the sideeffects encountered, the biochemical actions appear to be totally different.

\section{Reserpine}

The reserpine-like substances interfere with the retention in brain tissue of a number of amines, such as 5-hydroxytryptamine (5-HT) and the "catecholamines" (adrenaline, noradrenaline and hydroxytyramine), of which noradrenaline is the main representative in nervous tissue (Pletscher et al., 1956; Paasonen and Vogt, 1956; Holzbauer and Vogt, 1956). These substances are mainly concentrated in the hypothalamus and the tegmentum of the midbrain (Amin et al., 1954 ; Vogt, 1954), and 5-HT also in parts of the limbic system (Paasonen et al., 1957); they presumably play a role in the specialized function of these regions.

The biochemical action of reserpine is not restricted to the brain: 5-HT also disappears from platelets and intestine, noradrenaline from peripheral sympathetic neurones (Muscholl and Vogt, 1958), and sometimes from the adrenal medulla. We do not know whether the depleting action in brain is restricted to the amines just listed: there may be others of even greater functional importance which are as yet unidentified and which are also lost.

Though we cannot interpret the action of reserpine in terms of its interference with the binding of amines in brain because we do not understand the role played by these compounds in central function, the fact remains that reserpine has metabolic effects on hypothalamus, mesencephalon, and limbic system. In view of the role attributed to the limbic system in emotional processes (MacLean et al., 1956), this finding may be significant. It is corroborated by electroencephalographic evidence of seizure-like waves in the limbic system of reserpinized animals (Gangloff and Monnier, 1955; Killam and Killam, 1957). MacLean et al. (1956) caused functional inactivation of the hippocampus (part of the limbic system) of cats by injecting solid carbaminoylcholine into the tissue and setting off permanent synchronized neuronal activity simulating an epileptiform seizure; they observed that such cats had behavioural changes and alterations of conditioned reflexes which greatly resembled those atter reserpine: they also showed that reserpine slows down the turnover of sulphur in the hippocampus.

We do not know whether the interference with hippocampal function is related to the disappearance from those sites of the accumulated 5-HT. Altogether, the assessment of the relation between disturbance of function and state of the amines stored in special parts of the brain is at present entirely speculative. We do. however, know that in the peripheral nervous system, where conditions are less complex. the disappearance of noradrenaline from adrenergic neurones leads to failure of peripheral sympathetic activity. It is to be expected that. in prolonged treatment of psychiatric patients with large doses of reserpine, depletion must be such as to cause varying degrees of peripheral "functional sympathectomy." Analyses of urinary excretion of noradrenaline after administration of reserpine have confirmed this expectation by demonstrating a fall in the excretion of noradrenaline (Gaddum et al.. 1958). How far the disappearance of noradrenaline from the bypothalumus interferes with the activity of the sympathetic centres cannot at present be decided.

\section{Chlorpromazine}

Chlorpromazine is known to be a potent inhibitor of many enzymatic processes. and its depressing action on the brain is likely to be related to this property. The turnover of phospholipids, so important in cerebral function, is among the processes affected; and the respiration of electrically stimulated slices of guinea-pig brain is inhibited by very low concentrations of chlorpromazine (Ansell and Dohmen, 1956; Mcllwain and Greengard. 1957). In view of the general action of chlorpromazine on enzymes it is not surprising to find that its pharmacological actions are unusually numerous (Courvoisier et al., 1953). Many of these are undesirable side-effects from the point of view of the clinician; such are the depression of the bone marrow, the autonomic actions, the galactorrhoea, and the production of Parkinsonism, an effect chlorpromazine shares with reserpine.

The electroencephalographic findings after chlorpromazine are different from those after reserpine. The site most consistently affected appears to be the region of the reticular formation responsible for wakefulness and arousal: the threshold to stimuli such as pain. electric currents, and injections of adrenaline is raised, and the responses are shortened or even abolished (Hiebel et al., 1954; Himwich, 1955; Bradley, 1957 ; Bovet et al., 1957). However, the magnitude of this effect varies with the experimental conditions, an $J$ the importance attributed to it therefore with the individual experimenter. Some consider the therapeutic effects to be more closely linked with electroencephalographic changes in the limbic system, where high doses cause bursts of spikes which originate in the amygdala and can lead to generalized seizures (Preston, 1956). The attractiveness of this view lies in the fact that it provides a common basis for the action of reserpine and of chlorpromazine.

A third site of action of chlorpromazine is shown by the ingenious technique of "self-stimulation" (Olds et al., 1957). Olds discovered that animals carrying electrodes implanted in certain parts of their brain appear to derive satisfaction from electrical stimulation of these parts. When 
the animals have found out that treading on a lever will deliver a shock, they begin to operate the lever at frequent intervals. Rats given chlorpromazine no longer administer the shocks to their brain when the stimulating electrodes are implanted in the posterior hypothalamus, but continue self-stimulation when the electrodes lie in the anterior hypothalamus. The drug must therefore produce some important change in the posterior hypothalamus.

\section{Changes in Personality}

The use of these pharmacological observations for the explanation of the therapeutic action is limited by our lack of knowledge of cerebral function. If one assumes the therapeutic effect in psychoses to be due to an inhibition of overwhelming drives and irrepressible stimuli which are kept up by pathological processes in the brain, one can visualize these drugs as acting by inhibition of the metabolism in the offending regions of the brain. It is impossible to tell whether the limbic system is one of these offending regions and the spikes observed correspond to certain inhibitory phenomena occurring there, or whether the limbic system is stimulated by the drugs and such stimulation leads to useful inhibitions of other parts of the brain.

There is no doubt that chlorpromazine and reserpine produce profound changes in personality. Some assessment of the changes can be made by psychological experiments on normal people and animals. For obvious reasons, tests on man can only be carried out in a very limited way; in such an investigation on the effect of a single dose of the chlorpromazine analogue mepazine ("pacatal"; $\mathrm{N}(1-$ methylpiperid-3-yl)phenothiazine $\mathrm{HCl}$ ), highly skilled work had to be performed by the subject on the so-called triple tester. The result (Steinberg, 1957) was impaired performance, reduction in the tachycardia which normally accompanies effort, and lowering of the "level of aspiration," which means the improvement the subject expects to make on a repetition of the test.

More striking still are the effects observed in animals, to which the drugs can be given more freely: previously aggressive animals become tame and easy to handle; they develop an indifference to unpleasant stimuli shown in the loss of conditioned avoidance responses. Rats and monkeys, for example, were trained to avoid an electric shock by leaving a particular area of their cage when an acoustic or visual signal heralded the coming of the shock. After an injection of chlorpromazine or reserpine they failed to heed the conditioning signal, though they were perfectly capable of performing the motor effort required to avoid the shock (Smith et al.. 1957). Their behaviour had become inappropriate, and normal contact between animal and environment had been lost.

The results of these psychological tests suggest that a patient, though benefited while under treatment with one of these potent drugs, cannot be considered equivalent to a perfectly normal human being. The same conclusion is reached if we remember the general inhibitory effects produced on cerebral metabolism by these substances: it is inconceivable that inhibition should be entirely restricted to the unwanted cerebral activities.

\section{DRUGS USED MAINLY IN NEUROTIC AND NORMAL PEOPLE}

The drugs of this group lack the profound effects on brain metabolism seen in the first group; in fact, nothing is known about the biochemical side of their mode of action. Four substances, completely unrelated in chemical structure and in their pattern of pharmacological actions, will be discussed.

\section{Methylpentynol}

The first, methylpentynol ("oblivon "), is a higher alcohol and entered therapeutics as a hypnotic. Trotter (1953) introduced it into dentistry to reduce apprehension, and its success was proved by controlled double-blind trials. It then became important to ascertain by psychological tests whether it was safe to allow such patients to go home unescorted or to drive a car. It was found that the subjects, though unmistakably less inhibited in their behaviour by a dose of $0.5 \mathrm{~g}$., performed well in tests which mimicked driving activities (Trotter, 1954). On the highly exacting triple tester, however, the performance, level of aspiration, and tachycardia of effort were reduced (Dicker and Steinberg, 1957).

\section{Benactyzine}

Benactyzine ("suavitil," benzilic acid diethylamine ethyl ester $\mathrm{HCl}$ ) is a substance with an atropine-like action. Its effect on behaviour was discovered on animals (Jacobsen and Skaarup, 1955): a cat, used to obtaining food by pressing a lever and given benactyzine, went on pressing for food in spite of being greeted by a blast of air when operating the lever; when untreated, the cat refused to touch, and even hissed at, the lever. The drug also inhibits conditioned avoidance responses and thus has in common with reserpine and chlorpromazine the production of indifference towards disturbing stimuli. The results of tests on anxious people have been contradictory, and proof of efficiency in a controlled trial is still lacking (Davies, 1956; Coady and Jewesbury, 1956 ; Alexander, 1957 ; Raymond et al., 1957).

\section{Hydroxyzine}

Recently, promising reports have been published about the tranquillizing effects of a new antihistamine drug hydroxyzine ("atarax"). In a clinical trial on students suffering from psychological disorders (Becattini and Gallini, 1957), the drug, given in a daily dose of about $0.1 \mathrm{~g}$., scored higher than benactyzine. Hydroxyzine is a chlorobenzhydrol derivative, and chemically related to the antihallucinatory drug azacyclonol ("frenquel "). It appears to relieve anxiety without impairing critical faculties; it is also useful in conditions of agitated coma; such patients may require up to $1 \mathrm{~g}$. per day in divided doses (Ayd, 1957). It has fewer side-effects than benactyzine, but increases any tendency to seizures. It has in common with the tranquillizers hitherto discussed an inhibitory effect on conditioned avoidance reflexes (Levis et al., 1957). It raises the arousal threshold to sensory stimuli (Bradley, 1957), probably by an action on the reticular formation.

\section{Meprobamate}

The fourth drug, meprobamate (" equanil," " miltown "), is chemically and pharmacologically related to the central relaxant of skeletal muscle, mephenesin. Its tranquillizing action, however, is exerted by doses $(0.4-0.8 \mathrm{~g}$. several times a day) which are too small to affect muscular tone. Its mode of action differs from that of all other tranquillizers. Monkeys and rats become manageable and fearless, but the loss of fear does not lead to loss of conditioned avoidance reflexes. Thus-and this is in contrast to the behavioural effects of reserpine-chlorpromazine, benactyzine, and hydroxyzine, appropriate avoidance of noxious stimuli is not impaired (Berger, 1957), though inhibition ("freezing" of rats, for instance) by imminent danger is greatly reduced (Hunt, 1957). Specific effects on emotional behaviour were also shown in ducklings, which lost their fear of strange objects and the capacity of "imprinting "-that is, becoming attached to a parent duck or a decoy (Hess, 1957).

In man, double-blind clinical trials on meprobamate (Hollister et al., 1957) have shown improvement of anxiety neuroses and even of certain psychoses. In contrast to the effects of the other tranquillizers, it did not impair performance or level of aspiration in psychological experiments on the triple tester (Steinberg, 1957). These observations, and the findings with conditioned reflexes, show that the drug is capable of checking emotional responses while not interfering with skill, rational behaviour, and adequate responses to environmental stimuli. These would seem to be advantages for the ambulatory patient. It would be of the 
greatest interest to know the precise site and mode of action of meprobamate. When low doses are administered to monkeys, electroencephalographic changes (of a type associated with decreased activity) are found only in a number of thalamic nuclei (Hendley et al., 1957). This is no proof that the thalamus is the only or even the fundamental structure through which meprobamate exerts its clinical action, but it shows that the pattern of activity of this drug is different from, and less diffuse than, that of other tranquillizers, and that the thalamus plays some important part in its efferts.

\section{REFERENCES}

Alexander, L. (1957), Anm, N.Y.

Amin, A. H., Crawford, T. B. B., and Gaddum, J. H. (1954). J. Physiol. (Lond.), 126, 596.

(1956). Neurochem 150

Ayd, F. J. (1957). Psychotropic Drugs, ed. S. Garattini and V. Ghetti, p. 548. Elsevier Publ. Co., Amsterdam.

Becattini, U. and Gallini, R. (1957). Ibid.. p. 563.

Bovet. D., Mongo, (1957). Ann N. N. Yivestrini, B. (1957). Psychotroptc Drugs, ed. S. Garattini and V., Ghetti, p. 193. Elsevier Publ. Co., Amsterdam. Bradiey, P. B. (1957). ibid.. p. 207 ; p. 291.

Coady. A., and Jewesbury, E. C. O (1956). Brtt. med. J., 1. 485.

Courvoisier, S., Fournel. J.. Ducrot, R.. Kolsky, M., and Koetschet. P. (1953). Arch. int. Pharmacodyn., 92, 305.

Davies. E. B. (1956). Brit. med. J.i, $1,480$.

Dicker. S. E. and Steinbers H. (i957) Brit. J Pharmacol 12479

Gaddum, J. H., Krivoy, W. A., and Laverty, G. (1958). J. Neurochem. 2. 249.

Gangloff, H., and Monnier, M. (1955). Experientia, 11, 404.

lendley, C. D.. Lynes, T. E., and Berger. F. M. (1957). Tranquilizing Drugs, ed. H. E. Himwich, Publication 46 of the American Association for the Advancement of Science. Washington, p. 35

Hess, E. H. (1957). Ann. N.Y. Acad. Sci., 67, 724.4 . Paris, 30, 2346.

Hiebel. G. Bonvallet. M., and Dell, P. (1954). Sem. Ho.

Himister, H. (1957). Ann. N.Y. Acad. Sci., 67,789 .

Holzbauer, M. and Vort, M. (1956), J. Neurochem. 1, 8

Hunt, H. F. (i957). Ann. N.Y. Acad. Sci., 67, 712

Jacobsen, E. (195d) Strarup. Y. (1955). Acta pharmacol, (Kbh.) 11, 125

Killam, E. K., and Killam, K. F. (1957). In W. S. Fields, Brain Mechanisms and Drug Action, p. 71. C. C. Thomas, Springfeld, III.

Levis, S., Preat, S., Beersaerts, J., Dauby, J., Beelen, L., and Baugniet, V. (1957). Arch. int. Pharmacodyn., 109, 127.

Mcllwain, H., and Greengard, O. (1957). J. Neurochem., 1, 348.

MacLean, P.'D., Flanigan, S., Flynn, J. P., Kim, C., and Stevens, J. R. (1956). Yale J. Biol. Med., 28, 380

Muscholl, E., and Vogt. M. (1958). J. Phystol. (Lond.), 141, 132.

Olds, J., Killam, K. F.: and Eiduson, S. (1957). Psychotropic Drugs, ed. S. Garattini and V. Ghetti. p. 235. Elsevier Publ. Co., Amsterdam.
Paasonen, M. K., MacLean, P. D., and Giarman. N. J. (1957). J. Neurochem., 1, 326.

and Voogt. M. (1956). J. Physiol. (Lond.), 131, 617.

Pletscher, A., Shore, P. A., and Brodie, B. B. (1956). J. Pharmacol., 116, 84.

(1956). Ibid 118, 100.

Raymond, M. J., Lucas, C. J., Busley, M. L., and O'Connell, B. A. (1957). Brit. med. J., 2. 63.

Smith, R. P. Wigman, A. I., Wagman. W., Pfeiffer, C. C., and Riopelle. Steinberg. H. (1957). Communication to the British Pharmacological Society. July, 1957.

Trotter, P. A. (1953). Dental Practitioner, 3, 376.

Vogt, M. (1954). J. Phinstol. (Lond.), 123, 451.

\section{ANALOGUE COMPUTERS FOR RESEARCH ON LEARNING}

\section{BY}

\section{W. K. TAYLOR, Ph.D., A.M.I.E.E.}

The theories of learning that are being investigated at University College, London, with the aid of electronic analogue computing machines are based on a simple hypothesis that is now widely accepted by neurophysiologists-namely, that learning is due to changes in interneuronal transmission characteristics. According to this hypothesis, nerve impulses generated by the neurones that play a part in learning increase the transmission strengths of the paths that they follow. In discussing this hypothesis many problems arise concerning the physiological nature of the changes and the effects they would be expected to produce in various types of networks. The construction of neural analogues can help greatly in formulating and solving these problems.

\section{Network with History}

The transmission strength of the path from any neurone A to any other neurone $B$ may be defined as the change in the firing rate of $B$ produced by a change of one impulse per second in the firing rate of $\mathbf{A}$. This definition assumes that neurone $B$ is firing when the change in A's rate occurs, for if $B$ is inhibited to zero frequency the impulses from $A$ may not be sufficient to overcome the inhibition. The transmission strength of the path from $A$ to $B$ is said to be positive if $A$ tends to increase the firing rate of $B$ and negative if $A$ inhibits $B$.

The foregoing characteristics are simulated in the computer by arranging a network whose output depends upon its past history. The connexions between input and output are such that various pathways may be taken following a given input. Electronic counters count the number of impulses flowing in each path of the network under investigation. These counters control the transmission characteristics in proportion to their content. When visual learning is being studied a set of light-sensitive elements or "eye" is arranged to receive the input shapes and to generate input impulses at frequencies proportional to the distribution of light intensity. All the impulses are the same size, but the strength of the driving effect produced by each impulse on a recipient neurone analogue unit is increased in proportion to the content of the impulse counter.

Thus, if only a few impulses have traversed a given path since the start of a learning experiment, the counter content will be low and the impulses will have only a small driving effect on the units to which they are connected. Preferential paths of high transmission strength can be built up in a network of this type. A given stimulus pattern can be made to select a particular output if the flow of impulses is directed by a training procedure. This is what we believe happens when an animal, say an octopus, is trained to attack certain shapes and to avoid others. The impulses generated by the act of feeding or by an electric shock are thought to direct the visual impulses through paths that lead to the attack and escape mechanisms respectively. One of the reasons for constructing computing machines is to test such vague hypotheses and to examine in detail the properties of networks that reproduce the learning behaviour of animals when supplied with appropriate stimulus patterns. Without an actual model one is reduced to making so many unrealistic assumptions in order to make the problems manageable that any results are of purely theoretical interest.

\section{Neuronal Connexions}

In order to decide on the characteristics to be given to the analogues it is necessary to make some assumptions about the physical nature of the connexions between neurones. In the mammalian spinal cord the transmission probably takes place through chemically controlled synapses in which the sign of the transmission is either positive or negative and the strength can take any value from zero up to a maximum. It is possible that the maximum transmission strength may have a very large value if the axon of the afferent neurone branches into thousands of endings which synapse with the recipient neurone and cover its surface with boutons. Aided by a sufficiently strong and durable synaptic chemical transmitter a single afferent impulse might then produce a high-frequency discharge in the region of 1,000 impulses per second lasting for many milliseconds. It is known that a high-frequency discharge of Renshaw cells in the spinal cord in response to a synchronous volley can last for fifty milliseconds or more before the chemical transmitter is neutralized. Under these conditions a transmission strength of up to 100 may occur, and this is the maximum value allowed for in constructing the electronic analogue machines.

As has been stated, the learning theories under investigation are based on changes in transmission strength, and this implies that the changes must last as long as the learning 